\title{
The Development of a Recognition Geometry Algorithm for Hybrid - Subtractive and Additive Manufacturing
}

\author{
David Homar* - Franci Pušavec \\ University of Ljubljana, Faculty of Mechanical Engineering, Slovenia
}

In the last decade additive manufacturing of metal components has experienced enormous development. One of the most important achievements in this sector is the fact that nowadays it is possible to produce fully dense metal parts. Generally, additive manufacturing technologies are able to produce very complex geometries but are time and cost consuming for manufacturing of massive components. Machining technology, on the other hand, has the opposite characteristics. Both technologies, additive and subtractive, have advantages and disadvantages depending on the amount of material that need to be added or subtracted. The combination of these two technologies (i.e. hybrid manufacturing) results in a process where advantages of both technologies can be expected (cost, material consumption, etc.). Thus a novelty, the paper presents a development and analysis of software that analyzes the CAD model with geometry of the model and declares which part of model will be manufactured with machining and which will be produced by additive manufacturing. The software is evaluated on an industrial case from the field of injection mould inserts. Results show that such an automated algorithm decreases cost, better efficiency and nevertheless offer possibility to implement technology in industrial environment to improve manufacturing processes, i.e. in current case injection moulding process/technology.

Keywords: hybrid manufacturing, additive manufacturing, subtractive manufacturing, machining, conformal cooling channels

Highlights

- Description of hybrid manufacturing as combination of additive and subtractive technologies has been described.

- Hybrid manufacturing of injection mould tooling with conformal cooling channels has been analyzed.

- Newly developed geometry recognition algorithm to determine manufacturing technology has been presented and described in detail.

- $\quad$ Algorithm has been evaluated on an industrial injection moulding case.

- Conformal cooled injection mould insert improves the productivity and quality of injection moulded plastic parts.

\section{O INTRODUCTION}

Product design is significantly dependent on its manufacturing processes. Machining, which is one of the subtractive processes, has a number of limitations related to the complexity of the product geometry [1]. Design of most products, which are to be produced by machining, is adapted to the technology itself [2].

In the last decade, techniques that combine two or more manufacturing processes, such as subtractive and additive technologies, are gaining significant attention. This has resulted in many researches on the combination of subtractive and additive technologies. As a contribution to the field, in this paper an algorithm, which was developed for the purpose of being used with a hybrid manufacturing cell, is presented. The hybrid manufacturing cell was developed at institute SINTEF [3] to [5], where two manufacturing machines have been used/combined. The first machine is a Deckel-Maho 5-axis CNC milling center and the other is ConceptLaser M2 for selective laser melting of metal powders. The aim of the hybrid manufacturing cell is to automate the hybrid manufacturing process as much as possible, for the production of different products. The developed algorithm presented in this paper is a significant part of this automation chain. The desired operation of the control system in the hybrid manufacturing cell is to analyze the intended product CAD model with the mentioned algorithm and determine which parts are $\mathrm{c}$ be manufactured by the additive and which by the subtractive process.

The first attempt to combine benefits of additive and subtractive manufacturing was the low cost integration of an arc welding unit on a 3 -axis CNC milling center, presented in [6] and [7]. The main purpose of this research was to manufacture the near-net shape of the product by weld-deposition of material directly on the $\mathrm{CNC}$ machine table and then improve the quality of the product surface by milling. The idea is good, however, due to the rough nature of the welding process, the researched process demonstrates limited benefits of other additive manufacturing processes.

Several researchers have published work on the methodology for the evaluation of manufacturing complexity for both additive and machining manufacturing [8] and [9], specifying 
the manufacturability index and possible desired manufacturing technology. The manufacturability index has been specified to be dependent on the material and geometry, as well as other detailed specifications. In papers [8] and [9] the calculation of the manufacturability index from a CAD model was constructed basing on an octree decomposition. In the paper [10], researchers presented a new design for the manufacturing approach with machining and additive manufacturing combined. The methodology was illustrated on two industrial examples. The manufacturability index on the second example, taken from automotive industry, was calculated first for machining and then for additive manufacturing. Analyses show that additive and subtractive technologies have to be combined, while the CAD model has to be imaginarily split into two parts: a first module for machining and a second for additive technology, added directly onto the first module.

In the last years, researchers introduced newly developed hybrid manufacturing process planning methods to synthesize subtractive, additive and inspection processes [11] to [13]. With these methods, products can be manufactured from existing part material and be remanufactured into new products with new identities. The basis for hybrid manufacturing is the decomposition of the 3D CAD model into two or more subparts which are manufactured in sequence by machining and additive manufacturing. One of the main disadvantages of introducing additive manufacturing into a machining process is the manufactured part distortion which was therefore thoroughly investigated. Part distortion is the result of residual stresses that are a consequence of nonuniform heating and cooling. Authors have identified parameters influencing part distortion using the developed mathematical model and incorporated these parameters in an experimental design by employing the Taguchi design of experiments strategy. Layer thickness, height and length of the parts were found to have the most significant effect on part distortion.

Yamazaki published a paper [14], in which a newly developed Hybrid Multi-tasking machine named MAZAK INTEGREX i-400 AM is presented along with an experiment of adding Inconel 718 features on a Stainless Steel shaft. INTEGREX i-400 AM is basically a 5 axis milling machine with two different heads for laser metal deposition (LMD) integrated. The first one is a fine LMD head delivering a bead size of $1 \mathrm{~mm} \times 0.5 \mathrm{~mm}(w \times h)$, intended for additive manufacturing processes, where high accuracy is demanded. The second one is a high speed LMD head which enables higher deposition rate with a consequently reduced accuracy, delivering a bead size of $3 \mathrm{~m} \times 1 \mathrm{~m}(w \times h)$. The presented experiment consists of manufacturing an example shaft for oilenergy industry purposes, where the substrate shaft material is Stainless Steel alloy 316S31 and the added material is Inconel 718 powder. The presented hybrid application results in a significant reduction in tool consumption and material cost.

The group of researchers [15] developed a part complexity evaluation model for application in subtractive and additive technologies. STereoLithography (STL) models of different parts were taken for evaluation of manufacturing complexity. Manufacturing complexity was defined by the number of triangles in the model surface and the model square block volume. Additionally, manufacturing complexity, defined in this way, was compared to the manufacturing complexity, based on their own experiences with manufacturing processes. Based on that, guidelines for selecting appropriate manufacturing procedures were defined. Production is significantly dependent on the complexity of the product, especially when comparing subtractive and additive technologies. Even more, both technologies could/should be combined on one/same part/product. Therefore, hybrid manufacturing is inevitable.

\section{HYBRID MANUFACTURING}

Subtractive and additive manufacturing technologies have their advantages and disadvantages [16]. Hybrid manufacturing indicates a process, where one part is produced by two or more completely different manufacturing technologies and the advantages of each technology are used, while the disadvantages are eliminated [17]. In our case, good is to use subtractive and additive technologies on one part/product.

Machining is one of the few subtractive manufacturing technologies (milling, turning, etc.). Parts are manufactured by removing material from the workpiece with a sharp cutting tool with defined cutting geometry [18]. In current case 5-axis milling is going to be tested.

In case of additive technology the computeraided design (CAD) model is sliced into cross section layers using a specific software and a computer numerical control $(\mathrm{CNC})$ code or pictures of cross sections are then generated, depending on the type of additive technology being used. The most common additive technologies for metal products are electron beam melting (EBM), laser deposition technology (LDT) and selective laser melting (SLM). In current case focus is on SLM. SLM is a technology in which 
the high power laser beam is used to build metal parts by selectively melting the metallic powder layer after layer. At the beginning of the process, before the metallic powder is melted, it is spread in a thin layer above the emerging manufactured part. For this reason SLM technology is also known as one of the powder bed technologies.

\subsection{Hybrid Manufacturing - Benefits and Limitations of Both Technologies}

Each manufacturing process has some advantages and disadvantages. The aim of hybrid manufacturing is combining both processes in order to eliminate as much disadvantages as possible.

The machining process is able to produce products with a high surface quality and very good accuracy [19], as well as to achieve high production speeds. On the other hand, products with a complex geometrical structure are very difficult or sometimes impossible to machine because the cutting tool cannot reach some geometry on the part (internal channels, etc.). The reason for this limitation is that the shape of the cutting tool itself prevents access to some places where metal has to be removed.

SLM is the exact opposite to the machining processes. Every kind of geometrical shape can be manufactured by SLM as the manufactured part is built by adding material layer by layer. The biggest disadvantage of SLM, as well as other additive manufacturing processes, is bad surface roughness [20]. There are two main reasons for this. First is common to all additive manufacturing processes and it is known as the stair-stepping phenomenon. Because the product is created layer by layer, all this processes leave a stair on the surface for each layer. The second reason is the generated melt pool, where many complex physical phenomena are involved. The behavior of the melt pool depends on thermocapillary forces, melt pool dynamics, currents of chemical diffusion, wetting conditions, convective heat conduction, diffusive heat conduction, gravity and so forth. Another big disadvantage of SLM is that production times are very long.

From the economic point of view SLM is not suitable for manufacturing bigger parts with relatively simple geometry, because, in comparison to machining, this kind of geometry is too timeconsuming and expensive to produce.

Fig. 1 shows a graph of machined product costs dependence on the amount of subtracted material and additive manufacturing product costs dependence on the amount of added material to produce the final geometry. The cost of a machined product also increases with increasing shape complexity. However complexity of product shape does not affect the cost of product manufactured by SLM. From the graph it can be summarized that it is more economical to manufacture a larger proportion of the part by machining, followed by additive process.

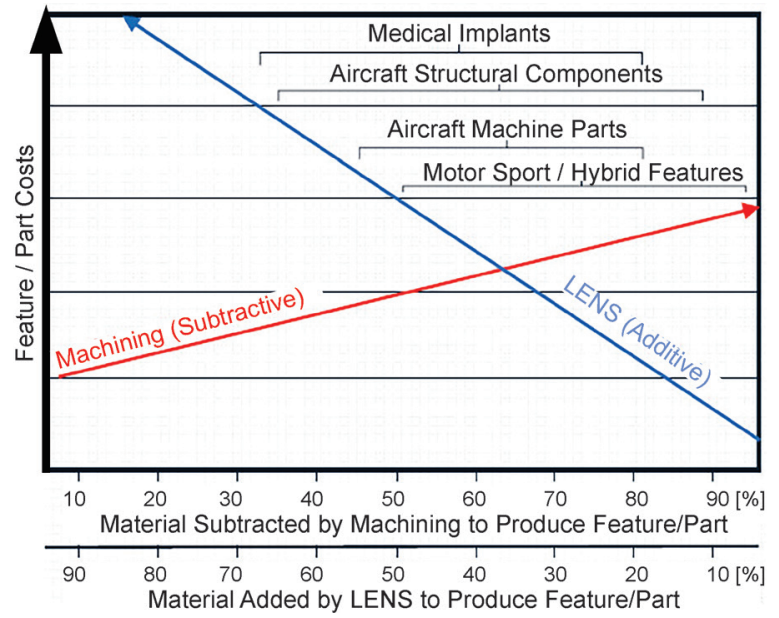

Fig. 1. The cost of production for a part produced by machining or additive manufacturing [21]

\subsection{Case Study - Injection Moulding Tool Insert with Conformal Cooling Channels}

In the last decade, in injection moulding industry is facing more and more frequently with the need for tools with conformal cooling channels. Conformal cooling channels are channels which are designed to adopt the shape of the injection mould tool cavity and core as much as possible, to improve and control the cooling process of the mould.

With conformal cooling, a tool or tool insert cooling efficiency, the uniformity of cooling and mechanical properties of moulded material are increased. These means that the cycle time and the cost of injection moulding are reduced and better product quality can be achieved. Cooling cycle time can be reduced up to $50 \%$ [22]. On Figs. 2 and 3 the difference between conventional and conformal cooling management is presented. Conformal cooling tool or tool inserts cannot be produced by conventional technologies, such as machining, because the cutting tool cannot reach the complex shape of the conformal cooling channels. SLM, on the other hand, is able to produce almost any shape, even complex internal shapes such as conformal cooling channels. However, the question that is raised is, can a portion of the part 
be produced on conventional and wich part. Therefore an algorithm has been developed for defining the portion of geometry for their sequential production (subtraction $>$ additive).

\section{DEVELOPED GEOMETRY SEPARATION ALGORITHM}

Optimized manufacturing operation sequence (OMOS) is a newly developed and proposed option in the automatization of hybrid manufacturing. The aim of the OMOS algorithm, which is implemented in the CAD computer software, is to analyze the geometric design of a product and to determine which part of the product cannot be manufactured by machining due to the complexity of the product geometry. This part is then separated from the initial CAD model and is meant to be produced by additive manufacturing. The remaining part of the initial CAD model is meant to be produced by machining [23] and [24].

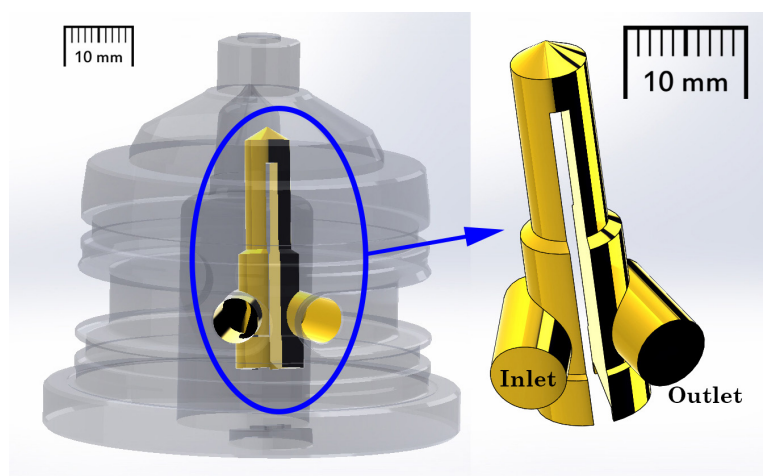

Fig. 2. Case study - conventional cooling management

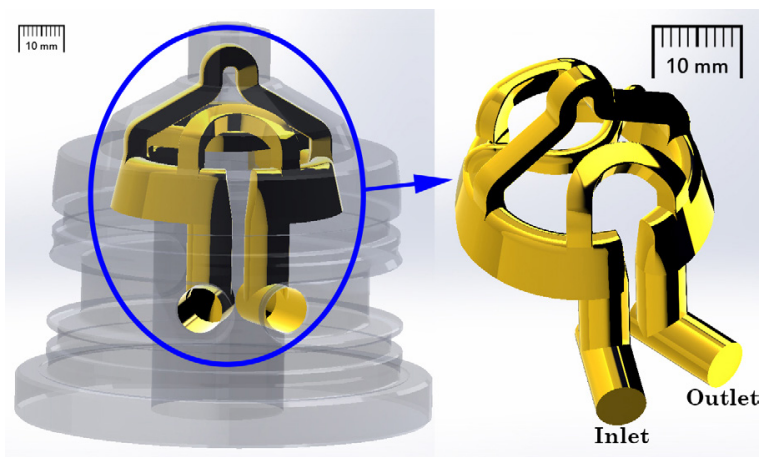

Fig. 3. Case study - conformal cooling management

The methodology for analyzing a geometric design is presented on Fig. 4 as a flowchart. The OMOS algorithm bases on the assumption that machining is basically a faster and a more economical technology than SLM. Therefore, the aim is to determine the biggest part of the product that can be produced by machining.

This algorithm has been developed and incorporated into the CAD software (SolidWorks). Besides finding the portion of the part that can be produced by subtractive technology, algorithm checks and implements also the limits and constraints of the additive manufacturing process.

SLM technology is one of the powder bed fusion (PBF) technologies which is significantly more accurate than the direct energy deposition technology that is usually used in machines for hybrid manufacturing. PBF technology allows to add material only on straight and horizontal surfaces of the part and demands a lot of time for preparation of the workpiece on the machine before performing the additive manufacturing process. Therefore, the complexity of dealt with additive manufacturing processes (PBF), limits the flexibility and determines constraints of this methodology.

For the verification and presentation of the OMOS algorithm a CAD model, which imitates an injection moulding tool insert with conformal cooling channels, was used. The CAD model is presented on Fig. 5. Fig. 5a presents the outer shape of the model. The transparent model, where the shape of the cooling channels is shown, is presented on Fig. 5b. The bottom part of the CAD model has straight cooling channels which can be manufactured by machining but the upper part has helix shaped channels which cannot be done by machining because the cutting tool cannot reach these faces of the cooling channels.

Vectors which represent cutting tools are a major element of the OMOS algorithm. At the start, the algorithm takes two points which are the boundary points of the CAD model. These two points are presented on Fig 6. The first point represents the minimum $x, y$ and $z$ coordinates of the analyzed part. The second point represents the maximum $x, y$ and $z$ coordinates. These two points are the key data for further analysis, because vectors are generated in the part's bounding box. The starting points of the vectors are $1 \mathrm{~mm}$ below the bottom or base face of the tool insert. All vectors are parallel and their direction is $(0,0,1)$, as it is shown on Fig. 7 . The starting point of the first vector is $\left(x_{\min }, y_{\min }, z_{\min }-1\right) \mathrm{mm}$. The next vector has its $x$ coordinate increased for $\Delta l$ and so on. The distance between adjacent vectors, $\Delta l$, is $0.1 \mathrm{~mm}$. Our analyses have shown that the distance $0.1 \mathrm{~mm}$ is small enough to get the correct height for splitting the part. If $\Delta l$ is reduced, the number of inserted vectors is increased and the analysis is more accurate, but it is done in a greater amount of time. For a better 


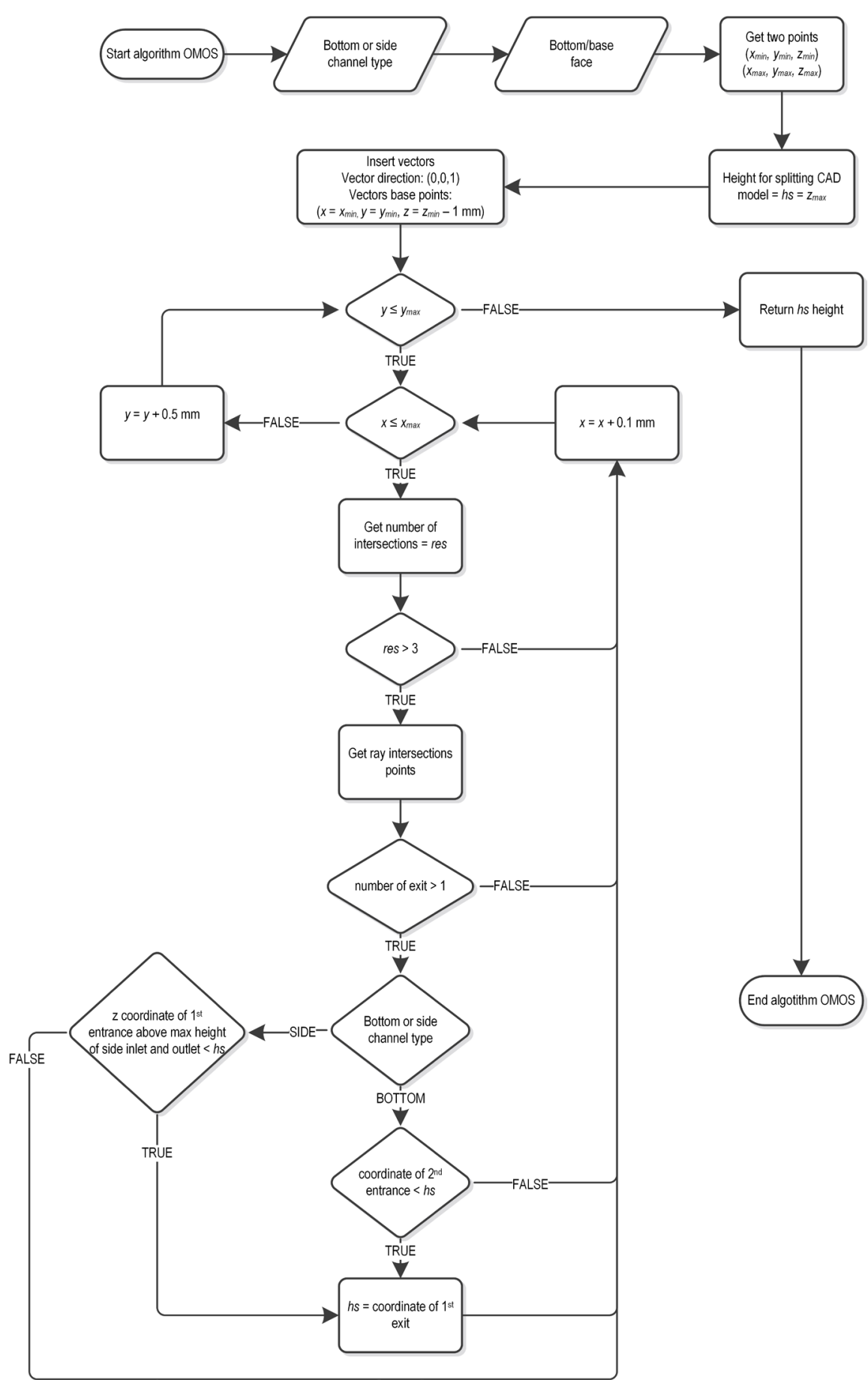

Fig. 4. Flowchart of OMOS algorithm

presentation $\Delta l$ on figure is bigger than $0.1 \mathrm{~mm}$ which was the value used in the case.

The program calculates the intersection points of vectors with the analyzed CAD model surfaces. Only vectors which have more than 3 intersections and more than 2 exits with CAD model surfaces are used for further analyze. The A-A crosssection of the CAD model in Fig. 6 is presented along with the inserted vectors in Fig. 8. The vectors that intersect the CAD model more than three times and exit the CAD model at least two times are presented in orange-dashed line and are used for further analysis. The algorithm 


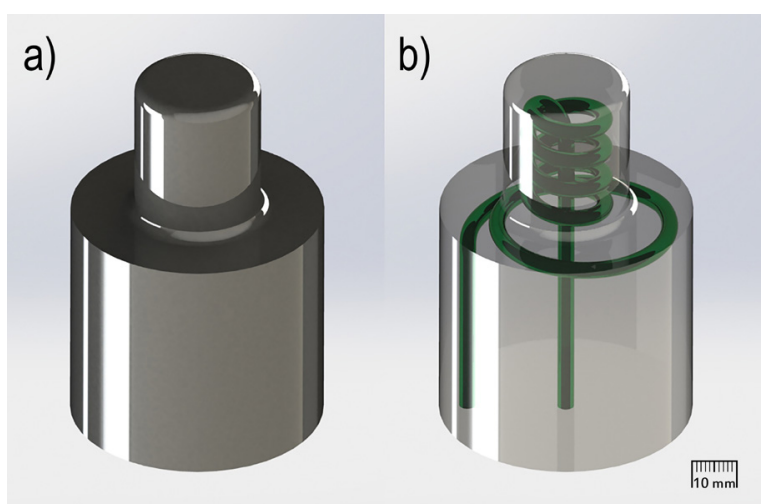

Fig. 5. CAD model of injection moulding tool insert with conformal cooling channels; a) the solid model and b) the transparent model

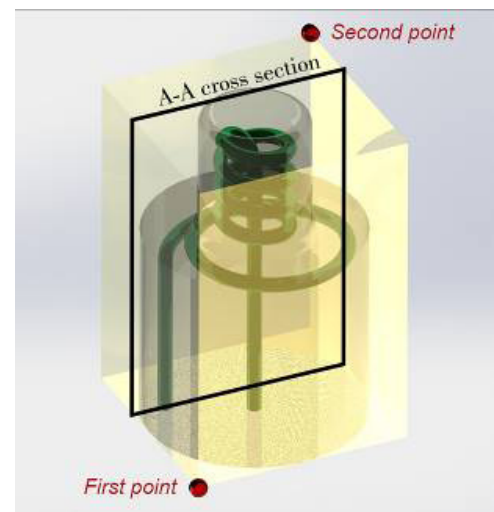

Fig. 6. Developed algorithm - boundary box of the CAD model with marked A-A cross section

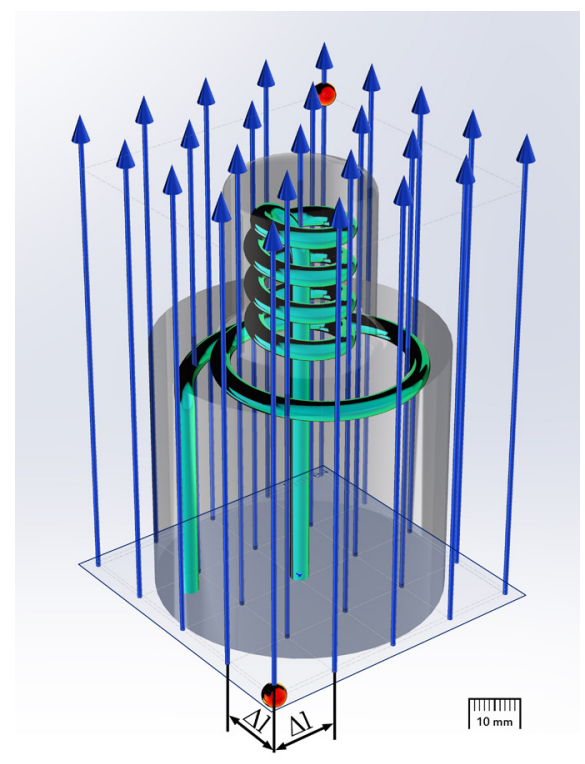

Fig. 7. Developed algorithm - inserted vectors

calculates the splitting height, $h s$, as the lowest of the $z$ coordinates of the first exit points of the analyzed

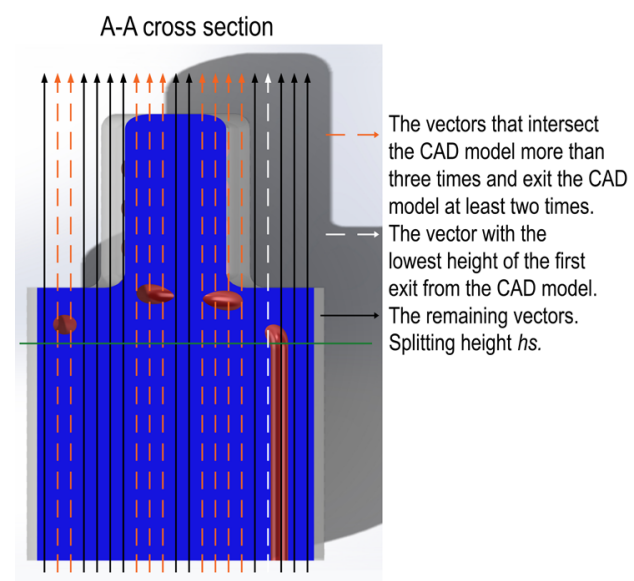

Fig. 8. Developed algorithm - A-A cross-section of the CAD model presented along with the inserted vectors

vectors in that case where the inlet and outlet channels are on the bottom face. In this case, the splitting height $h s$ is determined by the white-dashed vector in Fig. 8, as the height of the first exit from the CAD model is the lowest of the analyzed (orange-dashed) vectors, and is marked with the green horizontal line.

In the case, where the inlet and outlet channels are on the side face, the algorithm calculates hs as the lowest $\mathrm{z}$ coordinate of the first entrances of the analyzed vectors above the highest $\mathrm{z}$ coordinate of the side inlet and outlet channels.

\section{INCORPORATION OF OMOS ALGORITHM INTO CAD SOFTWARE}

The developed OMOS algorithm was implemented in SOLIDWORKS software package by Dassault Systems with the application programming interface (API) tool. With SOLIDWORKS API it is possible to automate and personalize software. That can be done from different programing languages. $\mathrm{C \#}$ was used in this work. The order of operations to be carried out when the OMOS software is started is shown in the flowchart on Fig. 9.

The CAD model of the injection moulding tool insert or another similar product, which is to be analyzed, has to be open in SolidWorks software where OMOS software was preinstalled. In software the user selects between choices of inlet and outlet channels being on the bottom or on the side face. User selects also the bottom face in the graphics area. Upon confirmation of selected face, the OMOS algorithm is executed. The OMOS algorithm returns the height to which the CAD model can be manufactured by 


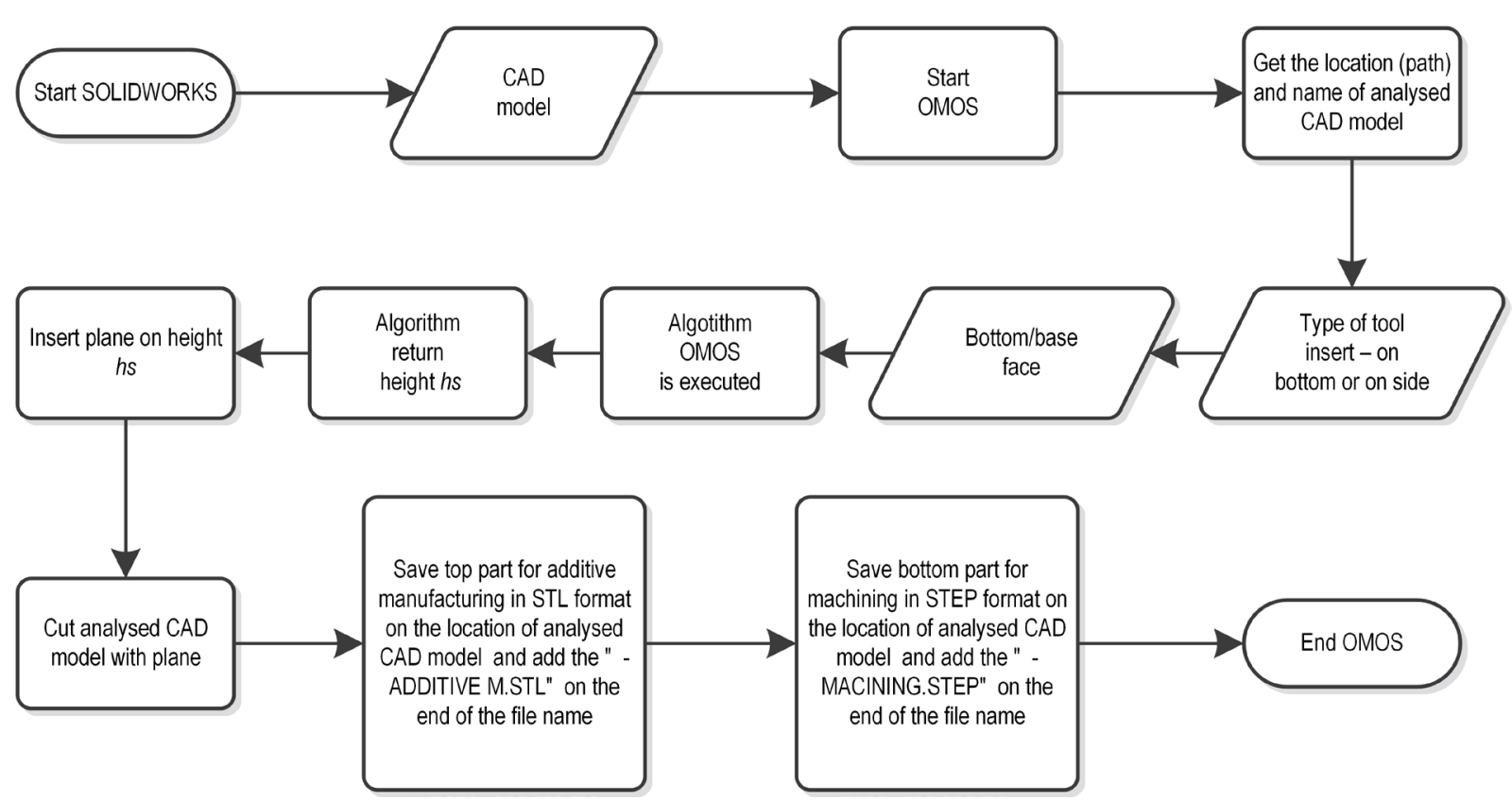

Fig. 9. Flowchart of developed algorithm and software OMOS

machining, hs. After that, a new plane which is parallel to the bottom face is generated on height $h s$. Thus, the part is split in two parts by the new plane. The bottom part is intended for machining and the upper part is intended to be manufactured by additive manufacturing.

Subsequently, the OMOS software automatically saves the bottom part as STEP, while this format is most often used for preparation of $\mathrm{CNC}$ tool path code. However, the upper part is saved as STL file that is a hollow CAD model where the surface of the model consists of only triangles. STL file format is standard for transferring CAD geometry between design programs and additive manufacturing equipment. These two files are saved in the same folder as the initially analyzed CAD model and can be directly used for both parts of hybrid manufacturing.

\section{USE OF THE SOFTWARE OMOS ON THE INDUSTRIAL CASE STUDY}

The OMOS software was used and evaluated on an industrial case of producing an injection mould tool insert for the mass production of tube shoulders. The CAD model of the mould insert with conformal cooling channels, which was already presented on Fig. 3 , has been analyzed. The distance between adjacent vectors was set to $0.1 \mathrm{~mm}$. The entrance and the exit of cooling channels were placed on rather on the side of the part than on the bottom face of the part. Thus, in the geometry recognition algorithm, the side channel type of tool insert was selected in window form (Fig. $10)$.

After the analysis, the CAD model was automatically split on the height of $27.88 \mathrm{~mm}$. Fig. 11 shows in cross section view where the CAD model of tool insert is split on the right height, because bottom part of the model can be manufactured by machining.

If the height of the splitting plane was just slightly greater, the bottom part could not be manufactured by machining, because the drill bit would not be able to reach the vertical holes. The resulting split CAD model, as an output from developed algorithm, is presented on Fig. 12. Based on this, the tooling insert was successfully manufactured by hybrid manufacturing. The final product, had to be finished by finishing subtractive process, and is presented on Fig. 13.

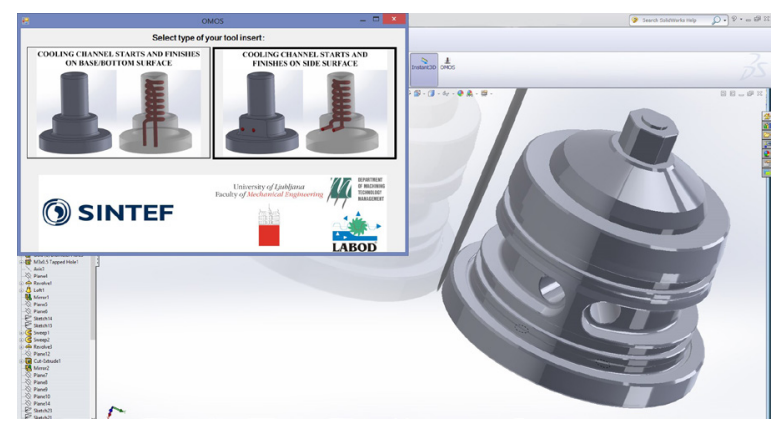

Fig. 10. Window form of the developed software 


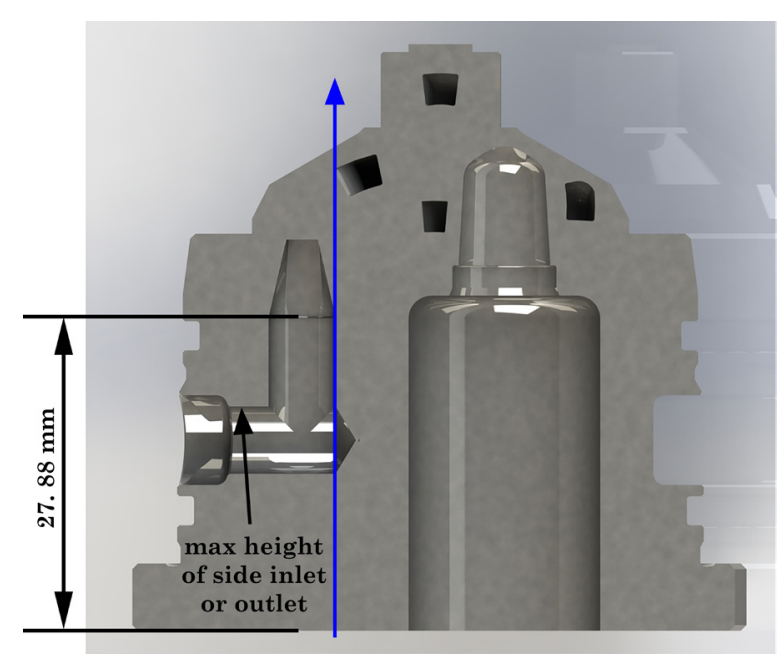

Fig. 11. Height of splitting

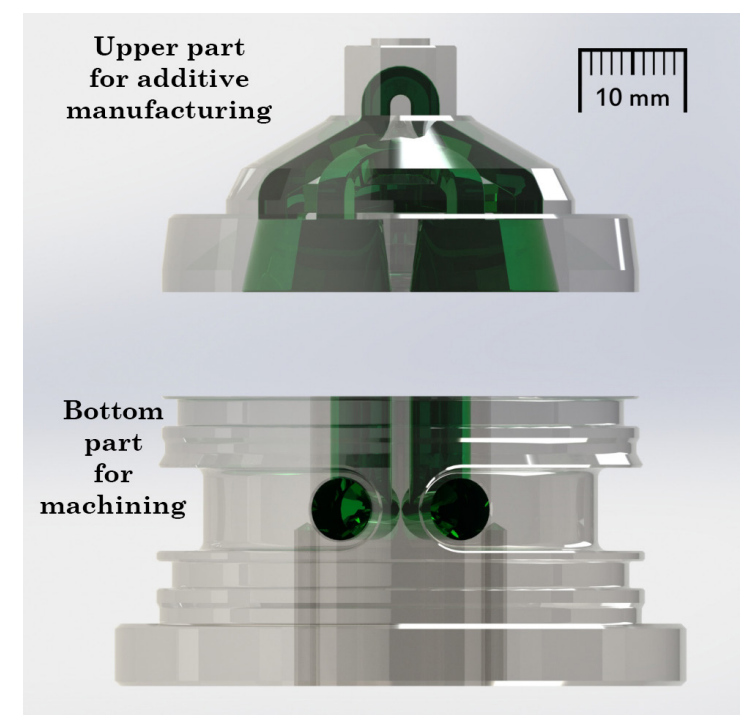

Fig. 12. Split part

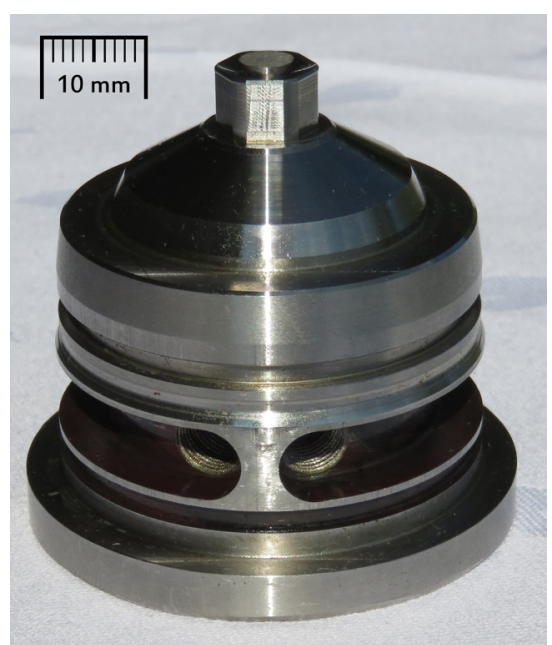

Fig. 13. Hybrid manufactured tooling insert

\section{VERIFICATION OF THE DEVELOPED OMOS ALGORITHM AND SOFTWARE}

Verification of the developed algorithm and software was carried out by analyzing production times and costs for injection moulding tool inserts, manufactured by additive and by hybrid manufacturing. The manufacturing of five injection moulding tool inserts that are needed for one complete injection tool, was analyzed. Following, the comparison of the production times and costs, comparing both manufacturing techniques, was performed.

Related to production times, the effective machining time was calculated for full additive manufacturing and hybrid manufacturing technique. The full subtractive method cannot be compared here, while it does not offer a possibility to manufacture such a geometrical characteristics of the products (channels). Table 1 presents the results for five injection moulding tool inserts, for both manufacturing techniques. The presented production times indicate the total time for manufacturing all five injection tool moulds that were manufactured simultaneously. In the case, where the inserts are manufactured only by additive manufacturing, the production time for 5 products is $86 \mathrm{~h}$. However, production time in the case of hybrid manufacturing, where the developed OMOS algorithm and software were used, is $42 \mathrm{~h}$. It can be seen that hybrid manufacturing is decreasing production times for more than $50 \%$. Therefore, the use of the hybrid manufacturing technique and the OMOS algorithm with software, significantly reduces production time, especially while the methodology is automated.

Table 1. Production time of the five injection moulding tool inserts using different techniques

\begin{tabular}{ccc}
\hline & Additive manufacturing & Hybrid manufacturing \\
\hline Production time $[\mathrm{h}]$ & 86 & 42 \\
\hline
\end{tabular}

Besides production times, crucial are also production costs. Fig. 14 shows the material and production cost comparison between both manufacturing techniques in the form of column charts. The blue columns show the comparison of material costs. The material cost for parts, manufactured by additive manufacturing, was more than 150 percent higher compared to the material cost for parts manufactured by the hybrid technique. The reason for that is that the price of the metal powder for SLM is 20 times higher than the price 
of the material in metal bars $(400 € / \mathrm{kg}$ vs. $20 € / \mathrm{kg})$. However, less material is used in additive process. For five injection moulding tool inserts a total of $2.2 \mathrm{~kg}$ of metal powder is needed when manufacturing only by additive manufacturing. However, in the case of the hybrid technique, $0.62 \mathrm{~kg}$ of metal powder and 4.57 $\mathrm{kg}$ of material for lower part, was needed. The reason for that is that the OMOS algorithm and software determined the smallest possible upper part, which has to be done by additive manufacturing, but the bottom part was manufactured by machining, where it has to be emphasized that raw material is significantly cheaper.

The orange columns in the chart present the comparison of production cost between additive and hybrid manufacturing of the five injection moulding tool inserts. The technology of SLM is a highly time consuming process. For the manufacture of the entire inserts by additive manufacturing, a total of $86 \mathrm{~h}$ is needed, what brings the production cost to $2580 €$ (30 $€ / h)$. However, in the case of the hybrid manufacturing and the use of the OMOS algorithm and software, only $33 \mathrm{~h}$ were consumed for the additive manufacturing process. In this case nine hours of the machining was performed before additive manufacturing. The total production cost of machining and additive manufacturing, in case of hybrid manufacturing, was $1440 €$. Verification of the developed algorithm was confirmed by fully functional parts in both dealt with technologies. Results highlight the improvements of such technology in sense of costs and cycle times. Reduced production cost justifies the use of the developed OMOS algorithm and software.

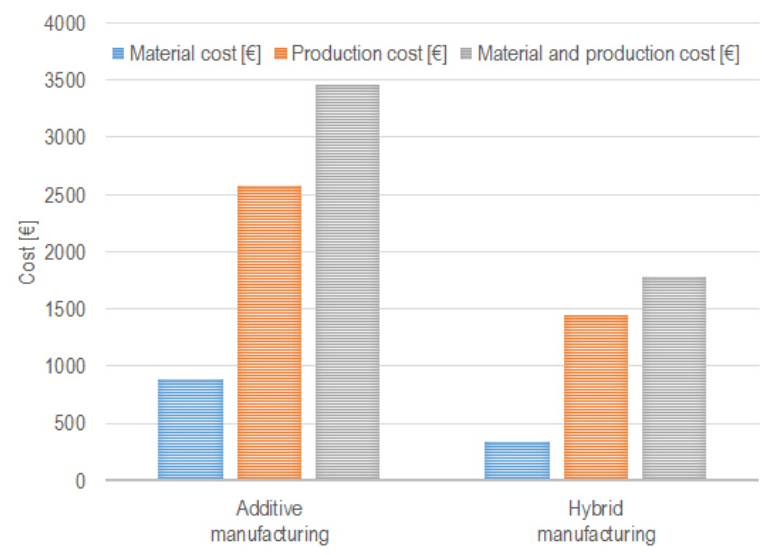

Fig. 14. The comparison of the material and production costs for additive and hybrid manufacturing

\section{CONCLUSIONS}

The implementation of additive technologies into current industry can bring gain in possibility for production of high complex parts (conformal cooling channels, etc.). However, problematic issues of such technologies are high costs and long production cycles.

Therefore, in this paper, the concept of hybrid manufacturing process, combining subtractive and additive process on single final part, is analyzed. For evaluation and characterization of the portion of geometry that can be made with subtractive/ additive manufacturing process, novel algorithm with belonging software OMOS is developed. Developed OMOS algorithm was thus introduced for automated recognition of manufacturing possibility of a specific part geometry. The algorithm determines the most advantageous division between which parts and features should be produced by either of the manufacturing principles. The OMOS algorithm is developed for a hybrid manufacturing cell where additive and subtractive technologies are used to produce especially injection mould tooling inserts. The algorithm was implemented in a commercial CAD software, and verified on industrial case study.

An industrial example has been taken from the field of tooling for injection moulding. The conventional manufacturing process has been compared with hybrid one, on production of injection moulding tooling. Results show that hybrid manufacturing can assure all the desired geometrical characteristics. Even more, the hybrid process can optimize the additive manufacturing process and produce functional features (cooling channels for conformal cooling of injection mould).

The OMOS algorithm and software viability wasadditionally verified by the analysis of the material and production costs, as well as the production (cycle) times. Saving time and production costs are the results of the OMOS algorithm and software, whose development was based on the assumption that machining is a faster and a more economical production technology than SLM.

Overall, the results of this work show the need for combining potential of additive manufacturing technologies with conventional (machining) technologies, and with it assure quality improvement, costs reduction, as well as possibility to produce high complex workpieces and with those improve the mass productivity and quality of final products. 


\section{REFERENCES}

[1] Sandberg, M. (2007). Design for Manufacturing: Methods and Applications Using Knowledge Engineering. PhD thesis, Lulea University of Technology, Lulea.

[2] Poli, C. (2001). Design for Manufacturing: A Structured Approach. Butterworth-Heinemann, Boston.

[3] Brotan, V., Bovie, K.M., (2012). The hybrid manufacturing cell: Determining key parameters in the integration of powder bed fusion with high speed milling. IEEE International Conference on Industrial Engineering and Engineering Management, p. 583-587, DOI:10.1109/IEEM.2012.6837806.

[4] Boivie, K., Dolinsek, S. Homar, D. (2011). Hybrid manufacturing; integration of additive technologies for competitive production of complex tools and products. 15th International Research/Expert Conference: Trends in the Development of Machinery and Associated Technology, p. 5356, Prague.

[5] Boivie, K., Karlsen, R., Ystgaard, P. (2012). The concept of hybrid manufacturing for high performance parts. The South African Journal of Industrial Engineering, vol. 23, no. 2, p. 106-115, Dol:10.7166/23-2-334.

[6] Karunakaran, K.P., Suryakumar, S., Pushpa, V., Akula, S. (2010). Low cost integration of additive and subtractive processes for hybrid layered manufacturing. Robotics and Computer-Integrated Manufacturing, vol. 26, no. 5, p. 490499, D0I:10.1016/j.rcim.2010.03.008.

[7] Karunakaran, K.P., Suryakumar, S., Pushpa, V., Akula, S. (2009). Retrofitment of a CNC machine for hybrid layered manufacturing. The International Journal of Advanced Manufacturing Technology, vol. 45, no. 7, p. 690-703, DOI:10.1007/s00170-009-2002-2.

[8] Kerbrat, O., Mognol, P., Hascoet, J.Y. (2010). Manufacturability analysis to combine additive and subtractive processes. Rapid Prototyping Journal, vol. 16, no. 1, p. 63-72, DOI:10.1108/13552541011011721.

[9] Kerbrat, O., Mognol, P., Hascoët, J.Y. (2010). Manufacturing complexity evaluation at the design stage for both machining and layered manufacturing. CIRP Journal of Manufacturing Science and Technology, vol. 2, no. 3, p. 208-215, DOI:10.1016/j.cirpj.2010.03.007.

[10] Kerbrat, O., Mognol, P., \& Hascoët, J.-Y. (2011). A new DFM approach to combine machining and additive manufacturing. Computers in Industry, vol. 62, no. 7, p. 684-692, DOl:10.1016/j.compind.2011.04.003.

[11] Newman, S.T., Zhu, Z., Dhokia, V., Shokrani, A. (2015). Process planning for additive and subtractive manufacturing technologies. CIRP Annals - Manufacturing Technology, vol. 64, no. 1, p. 467-470, D0l:10.1016/j.cirp.2015.04.109.

[12] Zhu, Z., Dhokia, V., Newman, S.T., Nassehi, A. (2014). Application of a hybrid process for high precision manufacture of difficult to machine prismatic parts. The International Journal of Advanced Manufacturing Technology, vol. 74, no. 5, p. 1115-1132, D0l:10.1007/s00170-014-6053-7.
[13] Zhu, Z., Dhokia, V., Nassehi, A., Newman, S.T. (2016). Investigation of part distortions as a result of hybrid manufacturing. Robotics and Computer-Integrated Manufacturing, vol. 37, p. 23-32, D0l:10.1016/j. rcim.2015.06.001.

[14] Yamazaki, T. (2016). Development of a hybrid multi-tasking machine tool: integration of additive manufacturing technology with CNC machining. Procedia CIRP, 18 th CIRP Conference on Electro Physical and Chemical Machining, vol. 42, p. 81-86, D0l:10.1016/j.procir.2016.02.193.

[15] Valentan, B., Brajlih, T., Drstvenšek, I., Balič, J. (2011). Development of a part-complexity evaluation model for application in additive fabrication technologies. Strojniški vestnik - Journal of Mechanical Engineering, vol. 57, no. 10, p. 709-718, DOl:10.5545/sv-jme.2010.057.

[16] Daneshmand, S., Aghanajafi, C. (2012). Description and modeling of the additive manufacturing technology for aerodynamic coefficients measurement. Strojniški vestnik Journal of Mechanical Engineering, vol. 58, no. 2, p. 125-133, DOI:10.5545/sv-jme.2010.238.

[17] Liou, F., Slattery, K., Kinsella, M., Newkirk, J., Chou, H.-N., Landers, R. (2007). Applications of a hybrid manufacturing process for fabrication of metallic structures. Rapid Prototyping Journal, vol. 13, no. 4, p. 236-244, DOI:10.1108/13552540710776188.

[18] Krolczyk, G.M., Krolczyk, J.B., Maruda, R.W., Legutko, S., Tomaszewski, M. (2016). Metrological changes in surface morphology of high-strength steels in manufacturing processes. Measurement, vol. 88, p. 176-185, D0I:10.1016/j. measurement.2016.03.055.

[19] Wojciechowski, S., Twardowski, P., Pelic, M., Maruda, R. W., Barrans, S., Krolczyk, G.M. (2016). Precision surface characterization for finish cylindrical milling with dynamic tool displacements model. Precision Engineering, vol. 46, p. 158165, D0l:10.1016/J.precisioneng.2016.04.010.

[20] Galeta, T., Kljajin, M., Karakasic, M. (2008). Geometric accuracy by 2-D printing model. Strojniški vestnik - Journal of Mechanical Engineering, vol. 54, no. 10, p. 725-733.

[21] Boivie, K.M. (2013). Metals: An Overview of Processes and Materials. Proceedings AM-DAGEN, Kista.

[22] Dalgarno, K., Stewart, T. (2001). Manufacture of production injection mould tooling incorporating conformal cooling channels via indirect selective laser sintering. Proceedings of the Institution of Mechanical Engineers, Part B: Journal of Engineering Manufacture, vol. 215, no. 10, p. 1323-1332, DOI:10.1243/0954405011519042.

[23] Gibson, I., Rosen, D.W., Stucker, B. (2010). Additive Manufacturing Technologies: Rapid Prototyping to Direct Digital Manufacturing. Springer, New York, D0I:10.1007/9781-4419-1120-9.

[24] Gardan, J. (2016). Additive manufacturing technologies: state of the art and trends. International Journal of Production Research, vol. 54, no. 10, p. 3118-3132, D0l:10.1080/0020 7543.2015.1115909. 